\title{
Integrating Building Information Management (BIM) in Civil Infrastructure Coordination: Application at LUSAIL Plaza
}

\author{
Mohab Mohamed Abotaleb \\ mabotaleb@QD-SBG.COM.QA \\ QD-SBG Construction Company, Doha, Qatar \\ Elisabeth Saab \\ SElisabeth@QD-SBG.COM.QA \\ QD-SBG Construction Company, Doha, Qatar \\ Mohamed AbdelZaher \\ mohamed.abdelzaher@sph-eag.com \\ SPH Joint Venture, Doha, Qatar
}

\begin{abstract}
The purpose of this case study is to highlight how the BIM modelling can lead to a smooth construction process for MEP (Mechanical, Electrical \& Plumbing), Civil, Architectural, and Landscape works, which can aid the engineers in various project phases. An exploratory approach on a complex mega-project case study (El-Sadek \& McCabe, 2017), where the project team was coached on exploring the BIM model to identify any clash and discuss with the technical team to come up with adequate solutions, which was done by holding twice a week regular meetings. This paper introduces the issues appeared during the early phases of the design process and continued all the way through the construction phases. While preparing the composite shop drawings, where each discipline/installation will have a clear corridor without interference with other disciplines/installations, and in a manner sufficient to ensure the avoidance of any clash that may arise during construction. However, what happens if the available corridor for all disciplines is very congested and insufficient to enable the designers from accommodating the space needed into coordination process? This case study triggers the need for identifying a new process in integrating BIM models in the coordination challenges through all the phases of mega-projects, as the complexity associated with mega projects appears to increase from one phase to another. From the lesson learned in this case study readers will know how integrating BIM in the coordination process in complex scale projects can decrease the clashes and improve progress of work during construction phase.
\end{abstract}

Keywords: LUSAIL; BIM; Coordination; Landscape; Civil; MEP

\section{INTRODUCTION}

The coordination between different disciplines plays a pivotal role in the success of resolving the provision and delivery of all facilities and especially those intertwining (Yazdani et al., 2015). In turn, identifying and managing interdependencies between the various elements of civil infrastructure works is a key element in establishing fullbodied coordination in the process and delivery of the provision, covering the overall spectrum during all the process from the Issued for Construction drawings (IFC) phase 
to the construction phase, passing through the other phases of shop drawings.

The construction industry is unlike any other industry, as there is a strong interrelation and coordination required across the entire project time. Coordination as a process of getting all disciplines together to enable construction team to perform work in an effective and efficient manner (Alaloul et al., 2016).

It is the guarantee for getting right information at the required schedule in order to improve productivity. Coordination is important for construction projects to manage the interfaces between the stakeholders. To enhance project performance, various coordination methods can be used, but coordination effectiveness needs to be assessed to find out if they are being used appropriately.

\section{LUSAIL PROJECT-A BRIEF DESCRIPTION}

Lusail Development site is located north of Doha-Qatar, and comprises of residential, commercial centers, hotels and community facilities. To realize their vision, LUSAIL Real Estate Development Company (LREDC), has come up with state-of-the-art discrete engineering projects comprising of various packages. Package CP07-B is a part of these projects and aims to establish a foundation for human, economic, social and environmental development, where the top management consists of: Owner: Qatari Diar Real Estate Investment Co. (QD), Client: LUSAIL Real Estate Development Company (LREDC), Main contractor: Qatari Diar (QD-SBG).

The Package CP07-B is divided into five main components: Infrastructure, LRT station, public car park, landscape including urban features, enabling works. The design scope of work under CP07-B comprises the following: Design \& build: Road A-1 troughs $-1.5 \mathrm{~km}$ long, Road A-1 tunnel (three levels) $-0.5 \mathrm{~km}$ long LRT station - structural and civil works, car parks -2 subterranean multi-story structures (east \& west) $-2,200$ stalls in total, bridge (at Junction no. 19), pergola (north and south troughs) - $320 \mathrm{~m}$ long, substations (7 no., $11 \mathrm{kV})$, utilities (electrical, mechanical, sewage, irrigation, storm and tunnel drainage network, etc.), At-Grade roads: Gas, district cooling \& pneumatic waste collection - design by MARAFEQ / integration by DAR, enabling works (excavation, shoring / dewatering) - design by specialist, Build: Landscape and public realm features (designed by $\mathrm{F}+\mathrm{P}$ ).

\section{RESEARCH DESIGN AND METHODOLOGY}

This paper focuses only on infrastructure works running between the plaza level and the car parking \& the LRT roof deck areas, where it introduces the issues appeared during the early phases of the design process and continued all the way through the construction phases, addresses the BIM for the coordination of architectural, landscape works and civil infrastructure works. Coordination begins at the stages of the design development where all the disciplines are being identified through different computer programs (software). These programs are used for coordination purposes, where all MEP clashes will be identified and sorted out, subsequent to which IFC's and shop drawings will be prepared and issued to the construction team on site for execution.

In the composite shop drawings, each discipline/installation will have a clear corridor without interference with other disciplines/installations, and in a manner sufficient to ensure the avoidance of any clash that may arise during construction. However, what 
happens if the available corridor for all disciplines is very congested and insufficient to enable the designers from accommodating the space needed into coordination process? This is where using BIM model in the issued for construction early phases, could not be satisfactory in solving all clashes.

The goal of this paper is to specify, formulate and develop the characteristics of a process using the BIM modeling technologies that will aid the engineers throughout the entire design process, from inception to completion, where it will become an essential tool to sort out all issues that may be encountered to cover the construction phase. The values of reaching this goal is to develop a new procedure for using BIM to its maximum $3 \mathrm{D}$ modeling tools that merges different $3 \mathrm{D}$ modeling programs to visualize and identify all the clashes during the design phase and extends to the construction phases to assist in resolving the issues that may arise, formulating a coordination platform that could have not been conceived without this technology. The methodology for this paper is a case study, done by exploring the clashes of the infrastructure works between the PLAZA and the roof decks of the car parking \& the LRT station, at the LUSAIL project.

\section{DEFINING BIM TECHNIQUES IN COORIDNATION PROCESS}

The aim of the paper is to define the corridors available/required for the infrastructure works below the plaza, formulating a process for the BIM modelling techniques, through exploring the various computer programs that can be fused into BIM model; identifying a process and highlighting its components for the BIM modelling that can be used from the early phases of design through and up-to the construction phase, through exploring a case study at LUSAIL project.

The coordination between the various systems in such a wide and complexed plaza usually include infrastructure works where the obstacles faced in that design arise due to the presence of a multitude of disciplines including multi MEP utilities, in addition to the impeded civil, architectural and landscape works, especially the involvement of various discipline engineers with different knowledge and experience, where the design/ coordination usually passes through a series of processes including workshops and using various computer programs culminating in composite/coordinated design/shop drawings free from clashes, a process that is usually done within the same engineering firm.

This case study introduces the LUSAIL plaza which includes very special landscape/ architectural items such as FOG fountains, water features \& huge photo cell canopies. In addition, from numerous planter/tree concrete boxes, it includes benches, walls and hand rails, also the buildings above the plaza includes 2 pavilion buildings and 8 pods required for the ventilation of the underground car parking.

Two huge car parks each comprising of 5 stories below the ground level of the plaza with an approximate $40,000 \mathrm{~m} 2$ plot area, a backfilled area required for the infrastructure utilities, between the plaza and the car parking roof decks, varying between 2 to $4 \mathrm{~m}$. LRT sub-station passing through the middle of the plaza with 2 entrances leading to the station with an approximate $40,000 \mathrm{~m} 2$ plot area, similarity backfilled area required for the infrastructure utilities, between the plaza and the LRT station, varying between $0 \mathrm{~m}$ to $4 \mathrm{~m}$. The total area of the plaza is $80,000 \mathrm{~m} 2$, bordered by 4 podiums for 4 towers each with basements reaching $25 \mathrm{~m}$ deep below ground level at the four corners. In addition to the physical limitations mentioned above, there are 3 designers involved in the LUSAIL 
projects, contributing towards the design of the plaza (DAR for the underground parking buildings, Foster and Partner for the plaza landscape, Pavilion and Pods \& Marafeq/ QRC for the LRT underground station), which hardened the coordination process. Thus it was a massive challenge to coordinate between all these different disciplines, packages and designers, prompting the design and build main contractor (QD-SBG) to assign designer for the preparation of a BIM model addressing all the above issues for the purpose of achieving IFC drawings free from clashes, and thus avoiding any delay that may occur due to miss-coordination during the stages of construction.

\subsection{Formulating BIM modelling}

Formulating a BIM model through collecting different 3D models from the different designers of the interconnected packages, in addition to build a 3D modelling for the details that have been unexploited or over-looked in the interferences between the different packages, was a great challenge where each designer used different 3D modelling software.

The challenge was finding a software that can fuse all these models into one federated BIM model. This was achieved by using Navisworks software, which allows for an effective identification inspection and reporting of interferences in a 3D project model.

The list of the software used in the archived BIM model is as follows:

Design authoring tools for buildings: Revit, Dynamo, 3DS Max, Sketch Up, Rinho, dRofus, Archicad, Bentley, and Grasshopper. Design authoring tools for infrastructure: AutoCAD Civil 3D, AutoCAD utility Design. Design review tool for building and infrastructure: Navisworks. With the use of the above software all the MEP disciplines were identified, including but not limited to (potable water, irrigation, foul sewer, storm water, gas, low voltage...etc.) also the buildings above, below and through which have been mentioned above.

It was essential for this latest fused model to be shared with all stockholders. Accordingly, the provisions of BS1192 were followed to prepare a Common Data Environment (CDE) to keep all the stakeholders on one sharing platform, in addition to using other platforms to share the fused model, which passed through a group of quality assurance QA/ quality control QC processes.

Later and after the coordination stage was processed where this wasn't only a clash detector from the 3D model but it was included also the clearance required by each system, in addition to the regulation required by the governmental parties. In light of the above a clash matrix was produced, after holding a series of meetings and workshops, a BIM model have reached with an acceptable level of clashes.

\subsection{Identifying the new BIM process}

After the IFC drawings were received by the main contractor, various packages were prepared and tendered/awarded to qualified subcontractors. Subsequently each subcontractor's engineering technical office and the main contractor's engineering technical office started to issue their shop drawings taking into consideration the coordinated BIM model. During this stage the subcontractors who were using up-todate systems and cutting edge technologies came up with different routes/corridors for systems and equipment satisfying all the requirements and specification different than 
the designed systems shown in the issue for construction stage.

Accordingly, new clashes were identified, which necessitated a new cycle of coordination on the BIM model in order to eliminate these new clashes that arose due to the occurring modifications/ introduction of new systems. Through this process the Level of Details (LOD) has increased considerably from 300 to 400 LOD, by decreasing and eliminating the clashes during the shop drawings stage. This supported the production of shop drawings to be ready for the construction phase.

During the construction phase, new clashes had arisen, as all the coordination, as described above, was done at the level of the engineering office, where the construction engineering team had done some rerouting based on site condition and errors. Moving or relocating any small detail at site will affect the coordinated BIM model. Accordingly, the sharing of the BIM model with the construction staff and engineers was essential and a good practice, where the construction engineers were able to visualize the systems and its adjacent schemes, in addition to the civil concrete works that may clash with the progressed systems. This can be achieved by introducing the site engineers to the BIM model by the mentoring of engineering technical office, which took the decision that the engineers at site should have a platform sharing the BIM model including all the systems (MEP utilities, civil, architectural \& landscape works). For the better understanding of the site engineers, where continuous coordination with the engineering technical office through the BIM modelling system had led to a decrease of clashes thus-leading to a smooth construction process.

\section{CONCLUSION}

The introduction of a new process for the BIM modelling through various phases of the project design and construction can lead to a smooth construction process for all MEP utilities, civil, architectural and landscape works. This can aid the engineers in various project phases using a new process for the 3D BIM modelling thus fulfilling the paper's goal, which is to specify, formulate and develop characteristics of a new process using the advantages of BIM modelling techniques at various project execution phases.

\section{REFERENCES}

El-Sadek, L. \& McCabe, B. (2017). Coordination challenges of production planning \& control in international mega-projects: A case study. Lean Construction Journal, pp. 25-48.

Yazdani, Saeid et al. (2015). Challenges of coordination in provision of urban infrastructure for new residential areas: The Iranian Experience. Macrothink Institute ${ }^{\mathrm{TM}}$, Volume 4, No. 1, p. 48.

Alaloul, Wesam \& Liew, M. S. \& Wan Abdullah Zawawi \& Noor Amila (2016). A framework for coordination process into construction projects. MATEC Web of Conferences Journal, Volume 66, p.79, DOI: 10.1051/matecconf/2016660007 